\title{
OPTIMASI PENILAIAN PADA E-LEARNING UNIVERSITAS MADURA DENGAN MENGGUNAKAN METODE SCAFFOLDING
}

\author{
Fauzan Prasetyo Eka Putra ${ }^{1}$, Moh Nazir ${ }^{2}$, Yasir Zain ${ }^{3}$ \\ ${ }^{123}$ Fakultas Teknik Informatika, Universitas Madura \\ Jl. Panglegur KM 3.5, Pamekasan - Indonesia 69313 \\ Telp. (0721) 787214 Fax. (0721) 700261 \\ e-mail : prasetyo@unira.ac.id
}

\begin{abstract}
Delivery of learning material in courses that are efficient in lectures at the University Madura, especially in the Faculty of Engineering and the Faculty of Science Teaching and Education is a difficult thing to do achieved, to be able to provide a good understanding and efficient in learning both mastery and understanding concepts, theories, methods or philosophy of a particular field of science obtained through in-process reasoning student learning and work experience. Some research has attempted to propose a solution in the delivery of learning, but very difficult to find a good method to use. In this research proposed a media optimization method learning by using scaffolding in the application elearning students in understanding the definition of material lectures, which is by using the method scaffolding will provide increased capabilities students in understanding the learning material, 6 strategies the scaffolding used in e-learning includes: modeling, instructing, explaining, questioning and hints, contingency management, and feeding back. Through e-learning system optimization planning, test results system conducted on 50 respondents for maleand female students produced a percentage of $63.82 \%$ for female students and $81.47 \%$ for male students as benefit values on the evaluation of e-learning system optimization planning.
\end{abstract}

Keywords - E-learning, Education, Scaffolding

\begin{abstract}
ABSTRAK
Penyampaian materi pembelajaran pada mata kuliah yang efisien dalam perkuliahan pada Universitas Madura khususnya pada fakultas Teknik dan Fakultas Ilmu Keguruan dan Pendidikan adalah suatu hal yang sulit untuk dicapai, untuk dapat memberikan pemahaman yang baik dan efisien dalam pembelajaran baik penguasaan dan pemahaman konsep, teori, metode atau falsafah bidang ilmu tertentu secara sistematis yang diperoleh melalui penalaran dalam proses pembelajaran dan pengalaman kerja Mahasiswa. Beberapa penelitian telah berusaha mengusulkan sebuah solusi dalam penyampaian pembelajaran, tetapi sangat sulit untuk menemukan metode yang baik yang harus digunakan. Dalam penelitian ini diajukan sebuah metode optimasi media pembelajaran dengan menggunakan scaffolding pada aplikasi e-learning Mahasiswa dalam memahami definisi materi dalam perkuliahan, yang mana dengan menggunakan metode scaffolding akan memberikan peningkatan kemampuan Mahasiswa dalam memahami materi pembelajaran, 6 strategi scaffolding yang digunakan pada e-learning antara lain: modelling, instructing, explaining,
\end{abstract}


questioning and hints, contigency management, dan feeding back. Melalui perencanaan optimasi system e-learning, hasil pengujian sistem yang dilakukan pada 50 responden (mahasiswa dan mahasiswi) menghasilkan persentase sebesar $63.82 \%$ untuk mahasiswi dan $81.47 \%$ untuk mahasiswa sebagai nilai manfaat atas evaluasi perencanaan optimasi sistem e-learning.

\section{Kata Kunci - E-Learning, Pendidikan, Scaffolding}

\section{Pendahuluan}

Saat ini Universitas dan Institusi mulai mengembangkan kampus virtual dengan menggunakan platform e-learning baik yang berbayar maupun yang gratis, hal ini didasari oleh ilmu pengetahuan dan teknologi berkembang dengan pesat. Perkembangan ini memiliki dampak semakin terbuka dan tersebarnya informasi dan pengetahuan dari dan ke seluruh dunia menembus batas jarak, tempat, ruang dan waktu. Pengaruhnya pun meluas ke berbagai kehidupan, termasuk bidang pendidikan di Universitas Madura. Pendidikan di Universitas Madura selalu membuka pikiran pada perkembangan ilmu pengetahuan dan teknologi tersebut, namun sebaliknya menjadi subyek atau pelopor dalam pengembangannya. Pendidikan di Universitas Madura merupakan suatu proses akademik yang tujuannya untuk meningkatkan nilai sosial, budaya, moral, dan agama, serta mempersiapkan mahasiswa menghadapi tantangan dan pengalaman dalam kehidupan nyata. Pendidikan di
Universitas Madura merupakan komunikasi terorganisasi dan berkelanjutan yang dirancang untuk menumbuhkan kegiatan belajar pada diri Mahasiswa. Mahasiswa mampu mengembangkan kemampuannya menemukan, mengelola, dan mengevaluasi informasi dan pengetahuan untuk memecahkan masalah pada dunia yang nyata dan ikut serta secara aktif dalam kegiatan bermasyarakat di lingkungannya. Untuk itu diperlukan proses pembelajaran yang efektif dan efisien yang menjadikan pembelajar menyerap informasi dan pengetahuan serta teknologi yang dipelajarinya sebagai bagian dari dirinya.

Akan tetapi, selama ini banyak penelitian menunjukkan bahwa pemahaman materi khusunya yang berhubungan dengan logika dan matematika sangat sulit dipahami oleh siswa maupun Mahasiswa karena dibutuhkan tingkat pemikiran formal dan abstrak yang hanya dapat dicapai bagi anak yang usianya cukup [1]. Kenyataannya di tingkat Mahasiswa pun kesulitan menyelesaikan masalah tersebut. 
Peningkatan pemahaman konsep pembelajaran dapat dengan scaffolding pada Mahasiswa. Scaffolding merupakan bentuk bantuan dan bimbingan yang diberikan kepada Mahasiswa yang mengalami kesalahan ketika menjawab tugas agar Mahasiswa mampu mencapai tujuan belajar yang diharapkan yaitu memahami materi dan definisi formal fungsi. Scaffolding merupakan struktur sementara untuk membantu atau memodifikasi struktur yang lain, penggunaan scaffolding sebagai metafora dalam domain pembelajaran yang mengacu pada dukungan sementara yang diberikan untuk menyelesaikan tugas, ketika Mahasiswa tidak mampu menyelesaikannya [2].

Scaffolding merupakan struktur sementara untuk membantu atau memodifikasi struktur yang lain, penggunaan scaffolding sebagai metafora dalam domain pembelajaran yang mengacu pada dukungan sementara yang diberikan untuk menyelesaikan tugas, ketika Mahasiswa tidak mampu [2]. Jadi, Scaffolding adalah bentuk bantuan dan bimbingan yang diberikan kepada Mahasiswa yang mengalami kesalahan ketika menjawab tugas melalui wawancara agar Mahasiswa mampu mencapai tujuan belajar yang diharapkan yaitu memahami definisi formal fungsi.

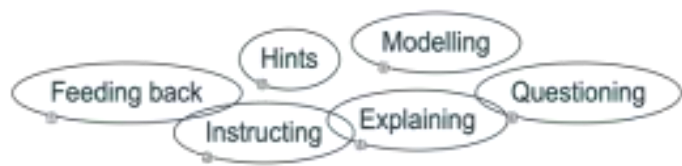

Gambar 1. Strategi scaffolding [3]

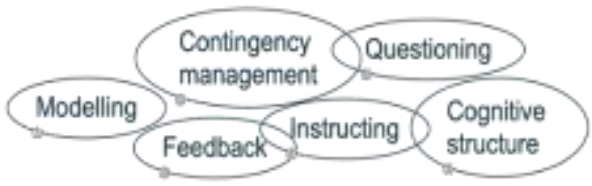

Gambar 2. Strategi scaffolding [2]

Gambar 1 adalah skema yang menyatakan bahwa scaffolding memiliki 6 strategi yaitu modelling (memberikan contoh), contingency management (pemberian reward dan punishment yang disesuaikan dengan progress Mahasiswa), feedback (pemberian umpan balik terhadap hasil belajar), instructing (pemberian informasi untuk melakukan suatu tindakan atau tugas bagi Mahasiswa), questioning (pemberian respon Mahasiswa), cognitive structure (pemberian penjelasan dan kepercayaan yang dapat mengorganisir dan memberikan alasan) [3].

Sedangkan gambar 2 yaitu feeding back, hints, instructing, explaining, modelling, dan questioning [2]. Berdasarkan hal tersebut, penelitian ini menggunakan 6 strategi diantaranya modelling, instructing, explaining, hints, contingency management, dan feeding back. 
Pada Tahun 2017 Universitas Madura mulai membuat dan mengembangkan $e$ learning. Dengan di implementasinya $e$ learning di Universitas Madura maka mereka membuat aturan tentang penggunaan dan pengembangan perangkat ajar tersebut. Pembelajaran dan Pengajaran

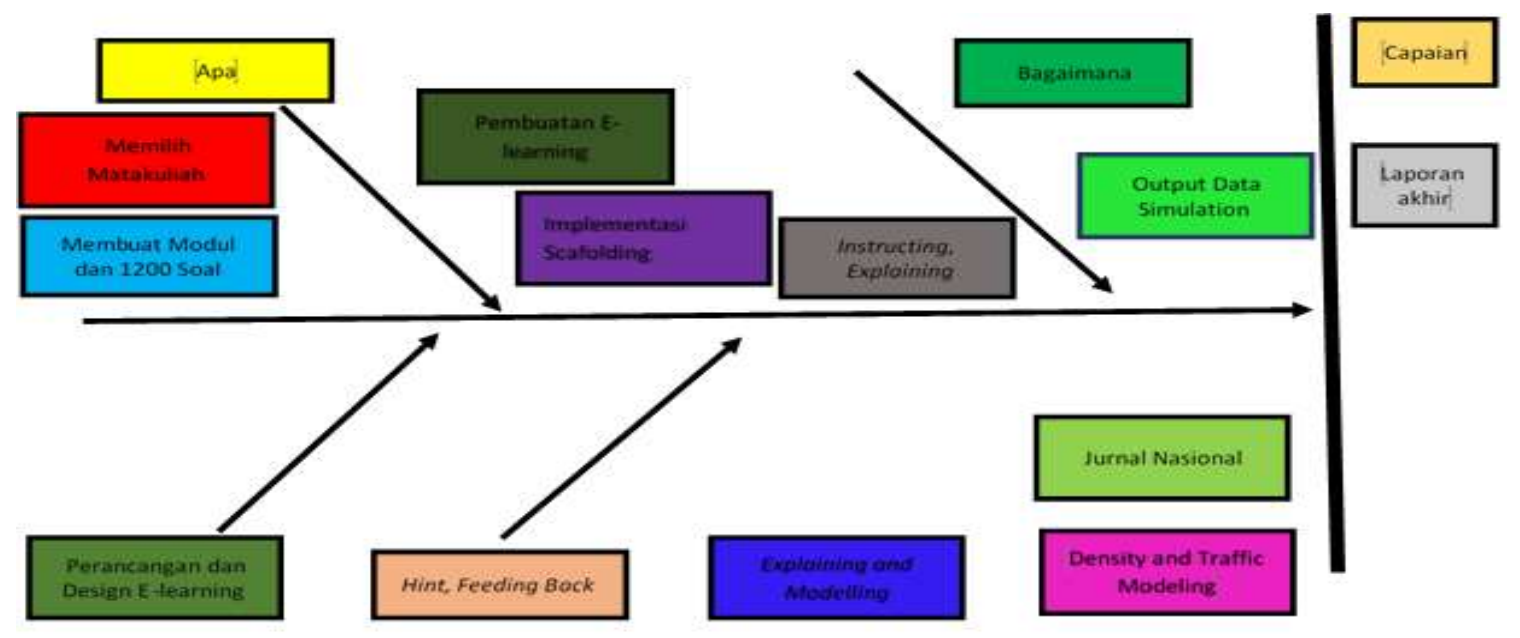

Gambar 3. Diagram alir penelitian

Online tersebut saat ini masih Madura selalu melakukan evaluasi setiap dimanfaatkan oleh 4 program studi tahun untuk mulai mengembangkan diantaranya Program studi teknik sipil, perangkat pembelajaran berbasis online informatika, keguruan dan ekonomi, dari ini, salah satunya dengan menambahkan 10 program studi yang terdapat di Universitas Madura. 4 program studi tersebut menawarkan dan menggunakan Virtual Open Learning (VOL) untuk meningkatkan pembelajaran selain menggunakan pembelajaran tatap muka. Dengan menggunakan monitring dan evaluasis Mahasiswa secara online meningkatkan kemampuan mengajar Dosen dan belajar Mahasiswa di program studi tersebut. Para Pengajar atau Dosen merupakan fasilitator para Mahasiswa dalam mengikuti perkuliahan maupun dalam prosen pengembangan kemampuan diri mereka, oleh karena itu Universitas Artificial Intelligence (Ai) ataupun dengan menambahkan dengan platform mobile agar semakin mudah digunakan baik oleh Pengajar atau Dosen maupun Mahasiswa itu sendiri.

\section{Metode Penelitian}

Lagkah-langkah penelitian yang dilakukan dalam mengoptimalkan sistem aplikasi e-learning dapat dilihat pada diagram Gambar 3.

Variabel dalam penelitan ini diukur dengan melihat beberapa faktor seperti pada Tabel 1. 


\section{HASIL dAN PEMBAHASAN}

\section{A. Evaluasi Sistem Berjalan}

Saat ini, sistem e-learning sudah cukup membantu yaitu dengan berubahnya sistem pengajaran tradisional ke komputerisasi. Flowchart Dosen dan Mahasiswa dapat dilihat pada Gambar 4.

Tabel 1. Construct, Indikator dan Item

\begin{tabular}{|c|c|c|c|}
\hline Construct & Indikator. & Item & Sources \\
\hline \multirow{4}{*}{$\begin{array}{l}\text { Generation of } \\
\text { individu and } \\
\text { exam }\end{array}$} & $\begin{array}{l}\text { 1. Pemilihan } \\
\text { individu }\end{array}$ & $\begin{array}{l}\text { 1. Kemampuan } \\
\text { beradaptasi } \\
\text { 2. Menyesuaikan dengan } \\
\text { parameter } \\
\text { 3. Menentukan } \\
\text { Development } \\
\text { Progression dari } \\
\text { matakuliah jaringan }\end{array}$ & \multirow{4}{*}{$\begin{array}{l}\mathrm{Min} \mathrm{Li} \text {, } \\
\text { et al. } \\
(2011)^{1} \\
\text { and } \mathrm{Li} \\
\text { Tang at } \\
\text { al (2018) }\end{array}$} \\
\hline & $\begin{array}{l}\text { 2. Perspeltif } \\
\text { system }\end{array}$ & $\begin{array}{l}\text { 1. Pengetahuan tujuan } \\
\text { penelitian } \\
\text { 2. Kemampuan } \\
\text { mahasiswa untuk } \\
\text { mencapai tujuan } \\
\text { 3. Saling berhubungan } \\
\text { dan bekerja sama }\end{array}$ & \\
\hline & $\begin{array}{l}\text { 3. Keterbukaan } \\
\text { dan } \\
\text { elksperimen }\end{array}$ & $\begin{array}{l}\text { 1. Promosikan } \\
\text { eksperimensi dan } \\
\text { inovasi } \\
\text { 2. Mengadopsi praktik- } \\
\text { praktik dan telnik } \\
\text { yang berguma dan } \\
\text { menarik } \\
\text { 3. Pengalaman dan ide } \\
\text { gebagai pembelajaran }\end{array}$ & \\
\hline & $\begin{array}{l}\text { 4. Transfer } \\
\text { pengetahuan }\end{array}$ & $\begin{array}{l}\text { 1. Didiskusikan dan } \\
\text { dianalisis dengan } \\
\text { berbagai macam } \\
\text { parameter } \\
\text { 2. Menggunakan } e- \\
\text { book,powerpoint, dan } \\
\text { video }\end{array}$ & \\
\hline $\begin{array}{l}\text { Make } \\
\text { environtment } \\
\text { of simulation }\end{array}$ & 1. Evaluasi & $\begin{array}{l}\text { 1. Penggunaan Hint, } \\
\text { Feeding back, } \\
\text { Instructing. } \\
\text { Questioning, } \\
\text { Explaining and } \\
\text { modelling, }\end{array}$ & $\begin{array}{l}\text { Renee and } \\
\text { Arash } \\
(2018)^{3}\end{array}$ \\
\hline
\end{tabular}

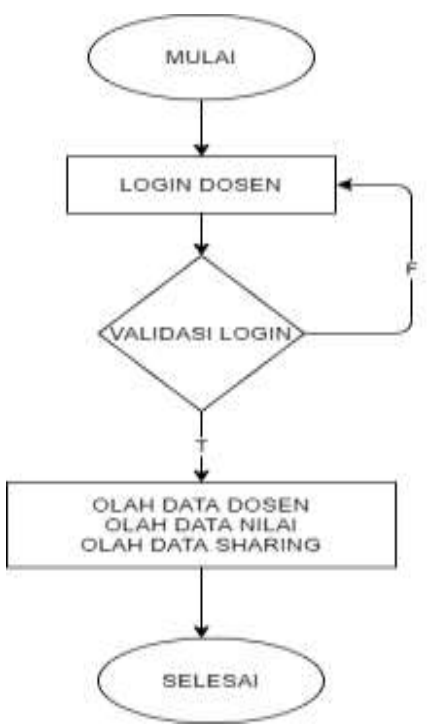

Gambar. 4. Flowchart Dosen sistem saat ini

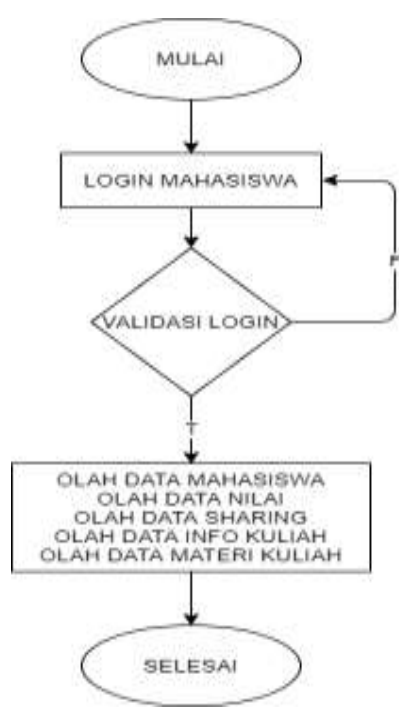

Gambar. 5. Flowchart Mahasiswa sistem saat ini

Dengan melakukan pengujian kepada koresponden (Mahasiswa dan Mahasiswi) sebanyak 50 orang terhadap sistem yang sedang berjalan, yang mana kami meminta mereka untuk mengisi kuisioner yang berisikan kategori seperti pada Tabel 2 dengan memberi skala nilai 1 hingga 5 
yang mana nilai - nilai tersebut akan dijelaskan dibawah ini.

a. Nilai 5:Sangat Setuju - sangat bagus.

b. Nilai 4:Bagus

c. Nilai 3:Biasa Saja

d. Nilai 2:Butuh Sedikit Pengembangan e. Nilai1:Tidak Setuju atau membutuhkan banyak perbaikan.

Maka dihasilkan data dari 50 korensponden seperti Gambar 6 berikut:

Table 2. Kategori penilaian e-learning dengan optimasi scaffolding.

\begin{tabular}{|c|c|c|}
\hline Kategori & Katerangan & Bobot Scaffolding \\
\hline 1. Modelling & $\begin{array}{l}\text { Proses atau Aktifitas yang menggunakan } \\
\text { contoh atau memotivasi menggunakan buku } \\
\text { digital, video dan podcast (audio) }\end{array}$ & $25 \%$ \\
\hline 2. Instructing & $\begin{array}{l}\text { Pembelajaran mata pelajaran dan ujian } \\
\text { diberikan petunjuk pengerjaan hingga } \\
\text { penilaian. }\end{array}$ & $15 \%$ \\
\hline 3. Explaining & $\begin{array}{l}\text { Pada e-learning ini Penjelasan yang diberikan } \\
\text { terkait dengan informasi detail yang diberikan } \\
\text { Dosen untuk menjawab dengan benar. }\end{array}$ & $15 \%$ \\
\hline \multirow[t]{2}{*}{ 4. Questioning and Hints } & $\begin{array}{l}\text { Questioning adalah membuat jumlah sesi soal } \\
\text { dan pemberian waktu pada setiap sesi soal, } \\
\text { misalnya sesi pertama soal 1-20 adalah } \\
\text { Aritmatika dengan waktu } 30 \text { menit dan } 21-40 \\
\text { adalah Geometri dengan waktu } 20 \text { menit. }\end{array}$ & $10 \%$ \\
\hline & $\begin{array}{l}\text { Hints adalah pemberian petunjuk pada } \\
\text { Mahasiswa untuk menyelesaikan masalah } \\
\text { tersebut, pada } \text { e-learning ini kami } \\
\text { memberikan } 3 \text { hint pada tiap sesinya }\end{array}$ & $10 \%$ \\
\hline 5. Contigency Management & $\begin{array}{l}\text { Pemberian nilai yang berikan oleh e-learning } \\
\text { untuk melihat permasalahan - kesulitan } \\
\text { pemahaman tiap siswa dalam pembelajaran. } \\
\text { Dengan berdasarkan dari nilai - capaian tiap } \\
\text { sesi soal pada e-learning }\end{array}$ & $15 \%$ \\
\hline 6. Feeding Back & $\begin{array}{l}\text { Setiap Selesai menyelesaikan materi -soal } \\
\text { tiap bab Mahasiswa diwajibkan mengisi } \\
\text { feedback/evaluasi pada bab tersebut bertujuan } \\
\text { untuk meningkatkan pola pembelajaran } \\
\text { pengajar dan peningkatan sistem e-learning } \\
\text { itu sendiri }\end{array}$ & $10 \%$ \\
\hline
\end{tabular}

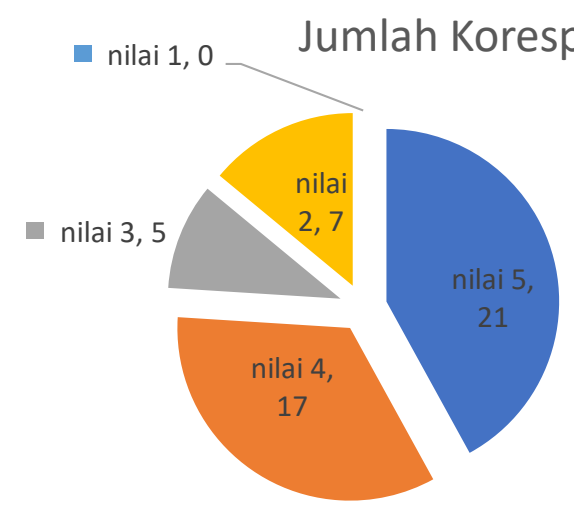

Gambar 6. Jumlah partisipan

berdasarkan semester atau grade

Dari data tersebut jumlah koresponden yang menggunakan e-learning dengan optimasi menggunakan scafollding yang menurut mereka sangat bagus sebanyak 21 
orang, yang menurut mereka cukup bagus 17 orang, serta yang menurut mereka biasa saja berjulah 5 orang, dan yang menurut mereka masih membutuhkan pengembangan sekitar 2 orang, dari data diatas kami melihat bahwa aplikasi ini sudah bisa mulai digunakan untuk kegiatan semester yang akan datang, pada penilaian bobot scaffolding dapat dilihat pada Tabel 2.

Dari data penilaian tersebut kami menggunakan partisipan uji coba pada Gambar 7 berikut :

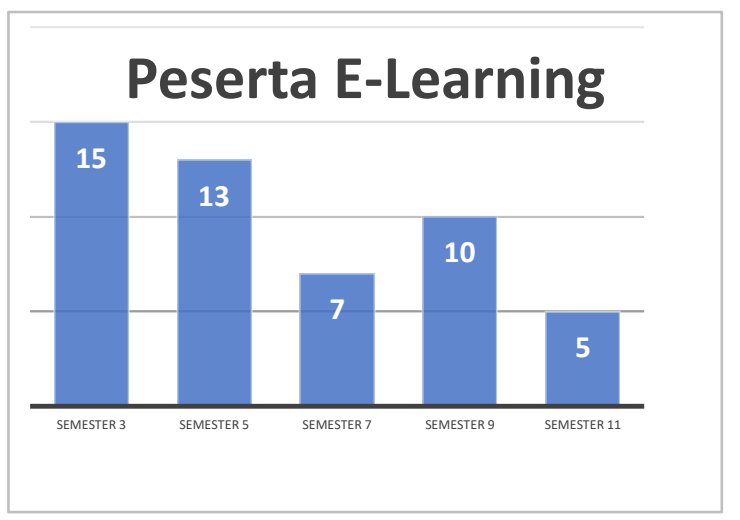

Gambar 7. Jumlah partisipan berdasarkan semester atau grade

Kami melakukan ujicoba optimasi $e$ learning menggunakan scaffolding melalui penilaian berdasarkan jenis kelamin. Oleh karena itu dari total 50 partisipan, akhirnya muncul angka persentase berdasarkan kelamin seperti pada Gambar. 8 di bawah ini.

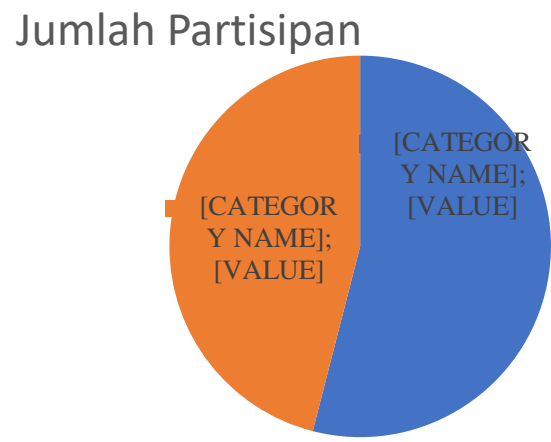

Gambar 8. Persentase jumlah partisipan berdasar jenis kelamin

\section{B. Hasil Evaluasi Optimasi}

Setelah melakukan pengembangan (optimasi) dengan menambahkan metode scaffolding pada e-learning terdapat perubahan flowchart Dosen maupun Mahasiswa yang dapat dilihat pada Gambar 9 dan 10 berikut:

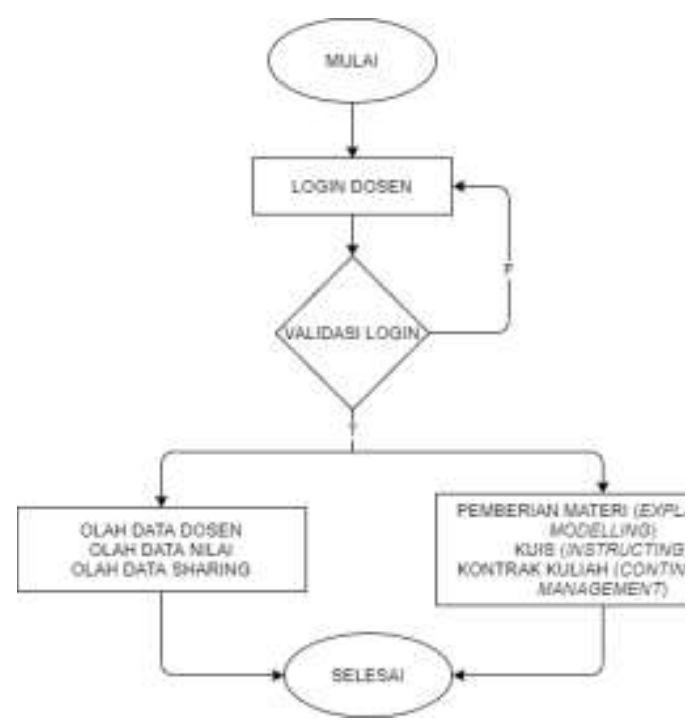

Gambar. 9. Flowchart Dosen optimasi sistem 


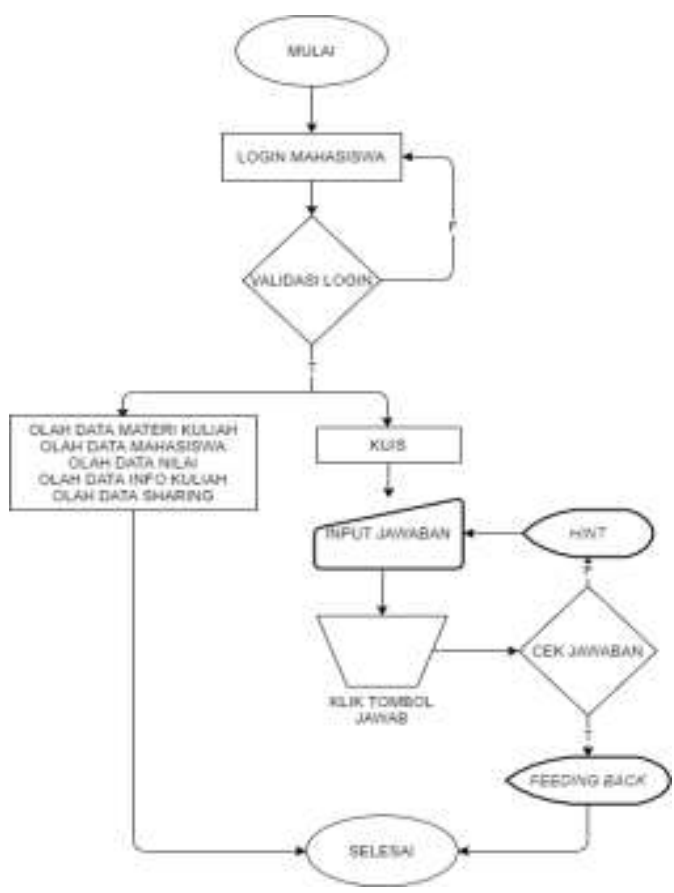

Gambar. 10. Flowchart Mahasiswa optimasi sistem

Hasil pengujian sistem setelah dilakukan optimasi yaitu pada Gambar 11 berikut:

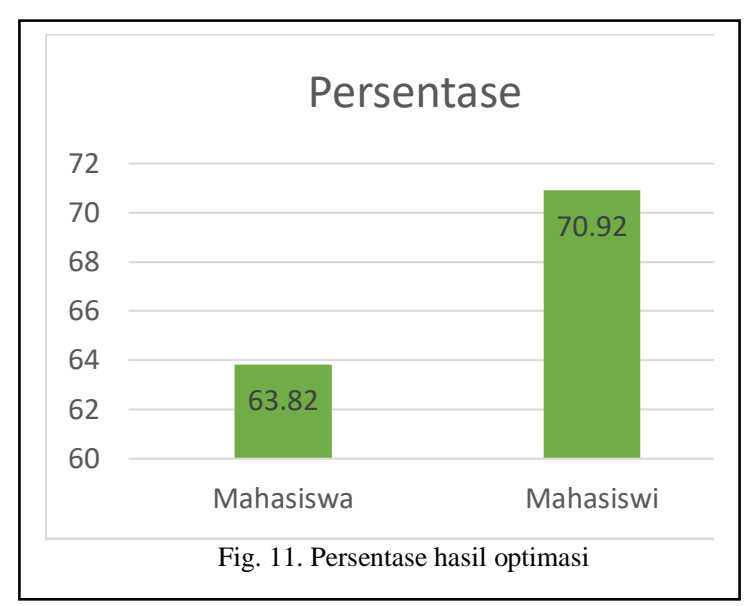

Melalui perencanaan optimasi sistem $e$ learning, hasil pengujian sistem yang dilakukan pada 50 responden (Mahasiswa dan Mahasiswi) menghasilkan persentase peningkatan hasil sebesar $63.82 \%$ untuk Mahasiswi dan $81.47 \%$ untuk Mahasiswa sebagai nilai manfaat atas evaluasi perencanaan optimasi sistem e-learning.

\section{Simpulan}

Berdasarkan uraian diatas, kesimpulan yang dapat diambil berdasarkan hasil rangkaian implementasi kerja. Kesimpulan tersebut adalah sebagai berikut :

1. Dapat meningkatkan pelayanan $e$ learning, memudahkan Dosen dalam menyampaikan materi dan Mahasiswa dalam mempelajarinya .

2. Mahasiswa dapat semakin mudah dalam mengerjakan tugas. Yang diberikan karena terdapat Scaffolding pada sistem e-learning.

3. Dengan adanya sistem yang dibangun dapat meningkatkan produktifitas pembelajaran.

\section{UCAPAN TERIMA KASIH}

Kami sebagai Penulis mengucapan terima kasih kepada Kementrian Riset Dan Teknologi atas dukungan selama pengembangan penelitian ini dan juga terima kasih kepada Universitas Madura.

\section{DAFTAR PUSTAKA}

[1] V. Sanchez and S. Llinares, "Four student teachers' pedagogical 
reasoning on functions," Journal of mathematics teacher education, Januari 2003.

[2] J. van de Pol, M. Volman, and J. Beishuizen, 2010. "Scaffolding in teacher-student interaction: a decade of research," Educ Psychol Rev, April

[3] R. G. Tharp, and R. Gallimore, "Rousing minds to life: teaching, learning, and schooling in social context," Press Syndicate of the University of Cambridge, 1988.

[4] Min, Li., Tang, Li.., \& Luoi, Junwei, etc. (2018). A novel scaffolding algorithm based on contig error correction and path extension. IEEE transaction on Computional Biology and Bioonformatics, Elsevier.

[5] Renee, M., Clark, M.., \& Mahboobin, A. (2018). Scaffolding to Support Problem-Solving Performance in a Bioengineering Lab - Case Study, Elsevier.

[6] Kjeldsen, T. H., \& Lützen, J. 2015. Interactions Between Mathematics and Physics: The History of the Concept of Function-Teaching with and About Nature of Mathematics. Science \& Education, 24(5), 543-559. https://doi.org/10.1007/s11191-0159746-x.
[7] Allen, Michael. 2013. Michael Allen's Guide to E-learning. Canada : John Wiley \& Sons.

[8] O'Shea, A., Breen, S., \& Jaworski, B. 2016. The Development of a Function Concept Inventory. International Journal of Research in Undergraduate Mathematics Education, 2(3), 279296.

[9] Purba, E. (2018, April). Models Of Sustainable Quality To Improve Implementation Of Quality System Of Qualified Enterprise. In Prosiding International conference on Information Technology and Business (ICITB) (pp. 1-4).

[10] Steele, M. D., Hillen, A. F., \& Smith, M. S. 2013. Developing Mathematical Knowledge For Teaching in a Methods Course: The Case of Function. Journal of Mathematics Teacher Education, 16(6), 451-482.

[11]Fitria, S. Y., \& SeptiliaArfida, H. Green Cloud Computing Ideas with Security Issues in Setting of Distributed Computing and Cloud Framework.

[12] KKNI-KPT DIKTI. 2013. Panduan Penyusunan Capaian Pembelajarn Program Studi di Penddidikan Tinggi sesuai Kerangka Kurikulum Nasional Indonesia. Tim penyususun KKNI-KPT Dikti. 